\title{
Awareness and prevalence of metabolic syndrome among high-risk individuals attending internal medicine clinics across Jordan
}

\author{
Rania Efaishat ${ }^{1}$, Rana Abu Farha ${ }^{2}$ and Eman Alefishat ${ }^{3 *}$ \\ ${ }^{1}$ Medical Supply Department, Directorate of Royal Medical Services, ${ }^{2}$ Department of Clinical Pharmacy and therapeutics, \\ Faculty of Pharmacy, Applied Science Private University, ${ }^{3}$ Department of Biopharmaceutics and Clinical Pharmacy, Faculty of \\ Pharmacy, The University of Jordan, Amman, Jordan
}

*For correspondence: Email: e.alefishat@ju.edu.jo; Tel: 0096265355000 ext 23366; Fax: 0096265355522

\begin{abstract}
Purpose: To examine the prevalence and awareness of metabolic syndrome (MetS) in high-risk individuals attending 30 internal medicine clinics in Amman, Jordan, and also to evaluate the various factors associated with increased risk of MetS among them.

Methods: This retrospective cross-sectional study was carried out across Amman, Jordan from October to December 2014. During the study period, 900 high-risk individuals (with hypertension, diabetes, central obesity and/or dyslipidemia) were recruited from thirty internal medicine clinics in Amman, Jordan. Data collection forms were filled based on patient interview and medical case file.

Results: The prevalence of MetS among high-risk individuals was around $40 \%$ (361/900), with around $79 \%(284 / 361)$ of MetS patients unaware of their condition. Older age, lower income and family history of premature cardiovascular diseases were associated with a higher prevalence of MetS.

Conclusion: Although MetS was found to be highly prevalent among high-risk individuals in this study, the awareness of the condition in this group is very poor. These findings support the need for educational programs that involve both health care providers and patients. These programs should especially target those at risk of MetS, in order to improve awareness of the concept of MetS.
\end{abstract}

Keywords: Prevalence, Metabolic syndrome, Jordan, Awareness, Risk factors

Tropical Journal of Pharmaceutical Research is indexed by Science Citation Index (SciSearch), Scopus, International Pharmaceutical Abstract, Chemical Abstracts, Embase, Index Copernicus, EBSCO, African Index Medicus, JournalSeek, Journal Citation Reports/Science Edition, Directory of Open Access Journals (DOAJ), African Journal Online, Bioline International, Open-J-Gate and Pharmacy Abstracts

\section{INTRODUCTION}

Cardiovascular diseases (CVDs) are the leading cause of death worldwide [1]. Despite the various and intensive management protocols used, many patients fail to achieve their desired clinical outcomes. Insulin resistance, elevated blood pressure, central obesity, atherogenic dyslipidemia, genetic susceptibility, hypercoagulable state, and chronic stress are among the most important risk factors of CVDs [2].
There have been numerous definitions of MetS [3-5], but the most commonly used definition at present is the one provided by the American Heart Association/National Heart, Lung, and Blood Institute which defines MetS as the occurrence of at least 3 of the following 5 cardiometabolic components: fasting blood glucose $\geq$ $100 \mathrm{mg} / \mathrm{dl}$, blood pressure $\geq 130 / 85 \mathrm{mmHg}$, triglycerides $\geq 150 \mathrm{mg} / \mathrm{dl}$, HDL-C $<40 \mathrm{mg} / \mathrm{dl}$ in males or $<50 \mathrm{mg} / \mathrm{dl}$ in females, waist 
circumference $\geq 102 \mathrm{~cm}$ (40 in) in males or $\geq 88$ cm (35 in) in females [5].

The constellation of three or more of the fore mentioned metabolic risk factors and their imminent link to insulin resistance and consequently to CVDs have suggested the notion of metabolic syndrome (MetS). Although it started as a concept, MetS is a diagnosis that is based on the presence of three or more of its components [5].There is an increasing need for raising the awareness of MetS, especially among patients at risk for diabetes and cardiovascular disease. Patients should be aware that the fore listed metabolic abnormalities are more likely to cluster than occur separately, and when they coexist, they are almost certainly related to insulin resistance and the associated hyperinsulinemia.

The prevalence of MetS continues to increase globally [6-8]. Prevalence rates reported in the literature are variable and related to the definition used, age, gender, race, and other factors [6-8]. Depending on definition, MetS affects between 21 and $38.9 \%$ of the US population [6,7]. In Jordan, the prevalence of MetS was found to be $37.4 \%$ in Jordanian individuals aged 25 years and older [8].

Introduction of lifestyle changes, that accommodate specific recommendations on diet and exercise, is the initial intervention of choice for high-risk individuals [9]. Pharmacological therapy is to be considered for those who fail to sufficiently modify their risk factors by following lifestyle changes [9]. Improving awareness of MetS is essential to execute risk reduction behaviors, and prevent its devastating complications, especially among high risk group. However, it is reportedly low $[10,11]$.

This study aimed to assess the prevalence and awareness of MetS among high risk individuals. It also aimed to investigate the various risk factors affecting MetS prevalence among this population.

\section{METHODS}

\section{Study design, setting and subjects}

This is a retrospective cross-sectional study that was carried out across thirty internal medicine clinics in Amman-Jordan. The study commenced in October-2014. In order to gain the participation of as many individuals as possible, a convenience sampling method was employed at the clinics over three months period depending on throughput rate of the clinics. Inclusion criteria were: 1) adult individuals 18 years of age and above, 2) with any confirmed component of MetS (NCEP/ATP III): confirmed diagnosis of diabetes, confirmed diagnosis of hypertension, waist circumference $\geq 102 \mathrm{~cm}$ in males or $\geq 88$ $\mathrm{cm}$ in females, recent triglyceride value $\geq 150$ $\mathrm{mg} / \mathrm{dl}$ (taken within the last 6 months), recent $\mathrm{HDL}-\mathrm{C}<40 \mathrm{mg} / \mathrm{dl}$ in males or $<50 \mathrm{mg} / \mathrm{dl}$ in females (taken within the last 6 months), 3) and willingness to participate in the study.

Research assistants (pharmacists) were trained to conduct the data collection process in the same manner (to decrease the risk of assessment bias). During the study period, a convenient sample of 900 individuals out of 990 who fulfilled the inclusion criteria were recruited (response rate $90.9 \%$ ). All participants were required to provide a written informed consent before the interview, participants' confidentiality was preserved. Study protocol was conducted in accordance with the World Medical Association Declaration of Helsinki guidelines [12]. Ethical approval was obtained from the University of Jordan (ref no. 68/2013-2014).

\section{Data collection}

All participants were assessed for their sociodemographic data including: participants age, gender, educational level, income, smoking, drinking alcohol, physical activities, dietary pattern, and whether there is any family history of premature CVDs (definite myocardial infarction or sudden death before age 55 years in father or other male first-degree relative, or before age 65 years in mother or other female first-degree relative). The components of metabolic syndrome were evaluated using patient medical records for hypertension, diabetes, recent triglyceride and recent HDL-C values (based on recent laboratory tests of up to 6 months). Waist circumference was also measured for all participants. All patients were asked whether they were aware of the presence of MetS or not.

\section{Statistical analysis}

Data were analyzed with Statistical Package for Social Sciences SPSS version 17 (SPSS, Inc., Chicago, IL, USA). Descriptive analysis was done using mean and standard deviation (SD) for continuous variables and percentage for qualitative variables. Chi-square test was used to evaluate differences between groups for categorical variables. All variables found to have significant association with having MetS in bivariate analysis were entered into logistic 
regression analysis to determine which factors have the strongest association. $P<0.05$ was considered statistically significant and all tests were two-tailed.

\section{RESULTS}

A total of 900 participants were recruited in this study. Mean age of participants was 55 years; females represented $52.1 \%$ (470) of the studied sample. The majority $62.7 \%$ (564) of participants had earned a bachelor's degree. The demographic details of the sample are summarized in Table 1.

In this study, the prevalence of MetS components was assessed for all participants (Figure 1). Among the studied components, central obesity was the most prevalent component, while low HDL-C was the least prevalent. The number of MetS components was evaluated; 361 participants had three or more components, resulting in a prevalence of MetS of around $40 \%$. When those participants were asked if they know that they suffer from MetS, only $21.3 \%(77 / 361)$ of those participants were aware of having the condition.

The investigation of factors affecting the prevalence of MetS showed that the prevalence was higher among older participants $(p=0.000)$. Lower education and lower income were also associated with higher risk of MetS $(p=0.000$ for both). The presence of positive family history of premature CVDs was found to be linked to higher prevalence of MetS $(p=0.028)$. No difference in MetS prevalence was related to gender or lifestyle habits (alcohol drinking, smoking, performing exercises, and dietary pattern).

Table 1: Socio-demographic characteristics of study participants and factors associated with risk of having MetS

\begin{tabular}{|c|c|c|c|c|c|}
\hline Parameter & & $\begin{array}{c}\text { Total } \\
\text { sample } \\
(\mathrm{n}=900)^{\#}\end{array}$ & $\begin{array}{c}\text { MetS }(\geq 3 \\
\text { components) } \\
(n=361)\end{array}$ & $\begin{array}{c}\text { No MetS } \\
(<3 \text { components) } \\
(n=539)\end{array}$ & $\begin{array}{c}P- \\
\text { value }^{\$}\end{array}$ \\
\hline \multirow[t]{2}{*}{ Age (Years) } & $<50$ years & $264(29.5)$ & $72(20.1)$ & $192(35.8)$ & $0.000^{*}$ \\
\hline & $\geq 50$ years & $631(70.5)$ & 286 (79.9) & $395(64.2)$ & \\
\hline \multirow[t]{2}{*}{ Gender } & Male & $430(47.8)$ & $172(47.6)$ & $258(47.9)$ & 0.948 \\
\hline & Female & $470(52.2)$ & $189(52.4)$ & $281(52.1)$ & \\
\hline \multirow[t]{2}{*}{ Educational Level } & Not educated/school & $336(37.3)$ & $163(45.2)$ & $173(32.1)$ & $0.000^{*}$ \\
\hline & BSc/Graduate study & $564(62.7)$ & $198(54.8)$ & $366(67.9)$ & \\
\hline \multirow[t]{2}{*}{ Monthly income } & $\leq 500 \mathrm{JD}$ & $406(46.1)$ & $190(53.5)$ & $216(41.1)$ & $0.000^{*}$ \\
\hline & $>500$ JD & $475(53.9)$ & $165(46.5)$ & $310(58.9)$ & \\
\hline \multirow[t]{2}{*}{ Active smoking } & Yes & $234(26.0)$ & $93(25.8)$ & $141(26.2)$ & 0.894 \\
\hline & No & $666(74.0)$ & $268(74.2)$ & $398(73.8)$ & \\
\hline \multirow[t]{2}{*}{ Alcohol drinking } & Yes & $22(2.4)$ & $8(2.2)$ & $14(2.6)$ & 0.721 \\
\hline & No & $877(97.6)$ & $352(97.8)$ & $525(97.4)$ & \\
\hline \multirow{2}{*}{$\begin{array}{l}\text { Performing } \\
\text { exercises }\end{array}$} & Yes & $248(27.6)$ & $94(26.0)$ & $154(28.6)$ & 0.405 \\
\hline & No & $652(72.4)$ & $267(74.0)$ & $385(71.4)$ & \\
\hline \multirow{2}{*}{$\begin{array}{l}\text { Family history of } \\
\text { premature CVD }\end{array}$} & Yes & $306(34.0)$ & $138(38.2)$ & $168(31.2)$ & $0.028^{*}$ \\
\hline & No & $594(66.0)$ & $223(61.8)$ & $371(68.8)$ & \\
\hline \multirow[t]{2}{*}{ Dietary Pattern } & Vegetarian & $43(4.8)$ & $15(4.2)$ & $28(5.2)$ & 0.474 \\
\hline & Non-vegetarian & $857(95.2)$ & 346 (95.8) & $511(94.8)$ & \\
\hline
\end{tabular}


${ }^{\$}$ Chi square test; ${ }^{*}$ Significant at $p<0.05$ significance level; ${ }^{\#}$ some questions have missing data

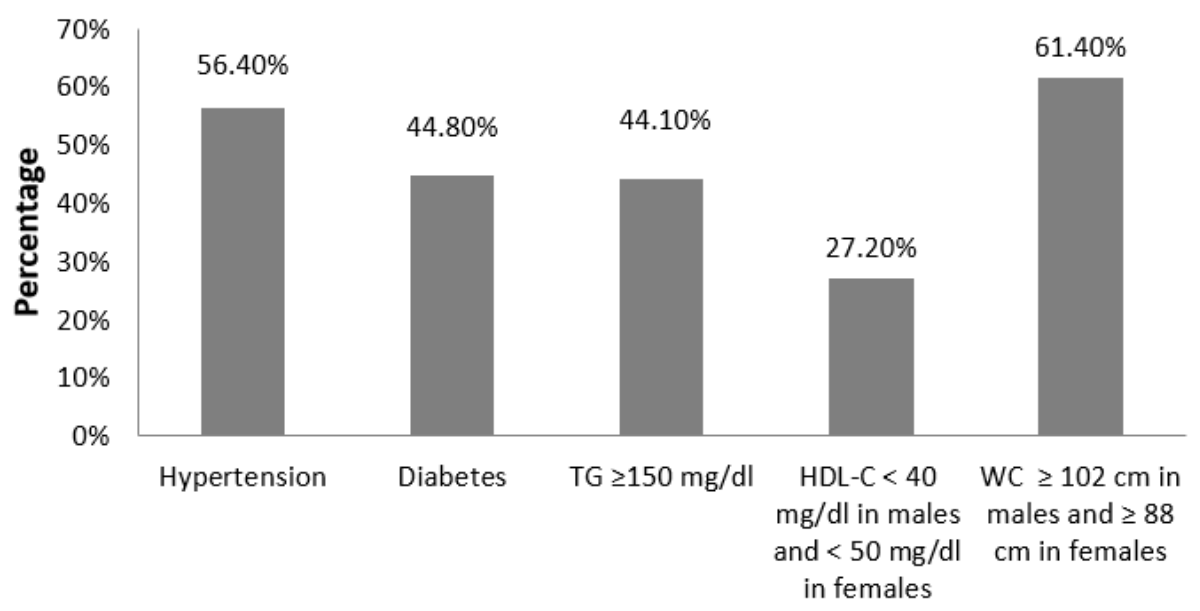

Figure 1: Proportion of variousMetS components among the study sample. Note: TG: triglyceride, HDL-C: high density lipoprotein-cholesterol, WC: waist circumference

Table 2: Results of logistic regression analysis of factors associated with risk of having MetS (having MetS coded 1, not having MetS coded 0)

\begin{tabular}{|c|c|c|c|c|c|}
\hline Variable & $\mathbf{B}$ & SE & $P$-value & Odds ratio (OR) & $95 \% \mathrm{Cl}$ for OR \\
\hline $\begin{array}{l}\text { Age (years) } \\
(0:<50 \text { years, } 1:>=50 \text { years })\end{array}$ & 0.763 & 0.164 & $0.000^{*}$ & 2.144 & $1.556-2.955$ \\
\hline $\begin{array}{l}\text { Family history of premature } \\
\text { CVD (0: No, } 1 \text { : Yes) }\end{array}$ & 0.362 & 0.148 & $0.015^{*}$ & 1.436 & $1.073-1.920$ \\
\hline $\begin{array}{l}\text { Monthly income } \\
\text { (0: <=500 JD, 1: >500 JD) }\end{array}$ & -0.365 & 0.154 & $0.018^{*}$ & 0.694 & $0.513-0.940$ \\
\hline $\begin{array}{l}\text { Educational levels } \\
\text { (0: Not educated/school, 1: } \\
\text { BSc/Graduate study) }\end{array}$ & -0.308 & 0.158 & 0.051 & 0.735 & $0.539-1.001$ \\
\hline
\end{tabular}

All variables in Tables 1 that were significantly associated with higher prevalence of MetS in bivariate analysis, were entered into final logistic regression model (Table 2). Among those variables, age $\geq 50$ years $(p=0.000$, OR 2.144 ) and the presence of family history of premature CVDs ( $p=0.015$, OR 1.436) were significantly associated with higher prevalence of MetS, while higher income level ( $p=0.018$, OR 0.694) was significantly associated with lower prevalence of MetS. A test of the final model goodness of fit using Hosmer and Lemeshow test, showed that the model was statistically reliable $X^{2}=2.565$ ( $p=$ 0.959).

\section{DISCUSSION}

This study aimed to assess the prevalence and awareness of MetS among high risk individuals attending internal medicine clinic in Jordan. It also aimed to evaluate the effect of various risk factors on the prevalence of this disorder.
The prevalence of MetS among high risk individuals was found to be $40 \%$ (361/900), this was similar to the prevalence rate reported by a previous study from Jordan (37.4\%) [8].The most interesting finding, and possibly the most alarming one, in this study is the fact that $78.6 \%$ (284/361) of MetS patients are unaware of their condition. This finding agrees with that reported by a multicentre Greek Study, where two third of subjects with metabolic syndrome were unaware of the MetS condition [11].This low awareness demonstrates the limited penetration of the concept of MetS among both patients and health care providers who most commonly tend to rather treat each component separately, instead of shedding light on the cluster of these conditions together in the form of MetS, and informing their patients about its associated risk of insulin resistance [13]. Since awareness of MetS is essential to implement risk reduction behaviors, that can potentially reduce the risk of CVDs, these results highlight the poor awareness of this condition and the necessity of 
educating, both health care providers and patients, about the clustering of these cardiometabolic components, and its associated increased risk of CVDs.

Among MetS components, central obesity was found to be the most prevalent $(61 \%)$, while low HDL-C was the least prevalent $(27 \%)$. In the literature the prevalence of different components varied considerably with some components being the most prevalent in some studies and least prevalent in other studies [14,15]. The high prevalence rate of central obesity in this study is consistent with the reported increasing rate in the literature [16].

The evaluation of risk factors and their association with MetS, older age was found to increase the risk of MetS. This conclusion is consistent with a previous report, where increasing age was found to affect the prevalence of MetS [14]. Individuals with lower income showed increased risk of MetS. Similar finding was found in a study from china, which highlighted a higher prevalence of MetS in females with lower income [17], while another study showed that higher income was associated with increased odds of having MetS among males [18].

The presence of positive family history of premature CVDs was associated with higher risk of MetS. This finding is consistent with a previous study that concluded a positive association of a positive family history of CVDs and the risk of MetS [8]. MetS is known to have a strong genetic component; higher prevalence of MetS components among parents is expected to be associated with higher prevalence of MetS components among their offspring generation [19].

In our study, no gender related differences in the prevalence of MetS were found. In the literature however, there were great controversial findings regarding the influence of gender on MetS prevalence. In many studies, prevalence of MetS was significantly higher in females than males $[15,20]$. But in a study by Sobko et al, they found that age-adjusted prevalence of MetS was over two times higher in males $(10.5 \%)$ than in females (3.7 \%) [17]. Other studies showed similar frequency of occurrence of the MetS for both males and females [21].

In this study, patients' education was found to be significantly associated with MetS prevalence in bivariate analysis, but not in multiple logistic regressions. Several previous studies evaluated the effect of educational level on the prevalence of MetS with conflicting results $[18,20,22]$. One study from Korea showed that the relative risk of MetS was two times higher in those with no or an elementary school education versus university graduation [22]. Another study showed that those with higher education had higher odds of having MetS after adjusting for age [18]. While the level of education, had no significant differences between patients with MetS and those without in a third study [20].

The effect of different lifestyle habits was previously investigated in the literature [8,20,23]. In our study, no difference in MetS prevalence was related to smoking or performing exercises. This finding was similar to previous studies where smoking status and physical activity did not show any statistically significant difference between individuals with MetS and those without $[8,20]$.We also concluded that dietary patterns showed no effect on MetS prevalence, which was inconsistent with finding from the Adventist Health Study 2 that showed a lower risk of MetS among vegetarians compared to non-vegetarians [23]. In our study alcohol consumption showed no beneficial or harmful effect on the prevalence of MetS, while a study from USA found that mild to moderate alcohol consumption is associated with a lower prevalence of the MetS [24]. In contrast another study showed that continuous drinking, especially moderate-to-heavy drinking, is associated with developing MetS in men [25].

\section{Limitations of the study}

Although this study has a relatively large sample size, we are aware of the main methodological limitation; since we relied on participants medical file to assess the presence of different MetS components (hypertension, diabetes, triglyceride and HDL-C) rather than evaluating these parameters by obtaining blood samples and measuring blood pressure values, accordingly our study might have underestimated the actual prevalence rate of MetS. This may result in excluding many high risk individuals who have either impaired blood glucose level (blood glucose $\geq 100 \mathrm{mg} / \mathrm{dl}$ ) or those with high blood pressure (systolic blood pressure $\geq 135 \mathrm{mmHg}$ and diastolic blood pressure $\geq 85 \mathrm{mmHg}$ ).

\section{CONCLUSION}

The findings of this study reveal a high prevalence rate of MetS among high risk individuals in Jordan. This study have also shown the unexpected, and alarming poor awareness of MetS among this high risk population who should, presumably, have better awareness of this condition. Awareness of MetS 
is a prerequisite for introducing lifestyle changes that can modify the risk of CVDs. Despite the worrying low awareness, it should be highlighted, that most of these patients at high risk, have chronic illnesses that will demand their regular visits for their physicians. This offers an opportunity for physicians to reach out to this important group of patients and educate them, and thus improve their awareness of MetS and its associated increased cardiovascular risk.

\section{DECLARATIONS}

\section{Conflict of Interest}

No conflict of interest associated with this work.

\section{Contribution of Authors}

The authors declare that this work was done by the authors named in this article and all liabilities pertaining to claims relating to the content of this article will be borne by them.

\section{REFERENCES}

1. Celermajer DS, Chow CK, Marijon E, Anstey NM, Woo KS. Cardiovascular Disease in the Developing World Prevalences, Patterns, and the Potential of Early Disease Detection. J Am Coll Cardiol. 2012; 60 (14): 1207-1216.

2. Li WJ, Xue H, Sun $K$, Song $X D$, Wang YB, Zhen $Y S$, Han YF, Hui RT. Cardiovascular risk and prevalence of metabolic syndrome by differing criteria. Chin med J. 2008; 121 (16): 1532-1536.

3. Alberti KG, Zimmet $P Z$. Definition, diagnosis and classification of diabetes mellitus and its complications. Part 1: diagnosis and classification of diabetes mellitus provisional report of a WHO consultation. Diabet Med. 1998; 15 (7): 539-553.

4. Balkau B, Charles MA. Comment on the provisional report from the WHO consultation. European Group for the Study of Insulin Resistance (EGIR). Diabet Med. 1999; 16 (5): 442-443.

5. Grundy SM, Cleeman JI, Daniels SR, Donato KA, Eckel $R H$, Franklin BA, Gordon DJ, Krauss RM, Savage PJ, Smith SC, Jr., Spertus JA, Fernando C. Diagnosis and management of the metabolic syndrome: an American Heart Association/National Heart, Lung, and Blood Institute scientific statement: Executive Summary. Crit Pathw Cardiol. 2005; 4 (4): 198-203.

6. Ford ES, Giles WH, Dietz WH. Prevalence of the metabolic syndrome among us adults: Findings from the third national health and nutrition examination survey. JAMA. 2002; 287 (3): 356-359.

7. Churilla JR, Fitzhugh EC, Thompson DL. The Metabolic Syndrome: How Definition Impacts the Prevalence and
Risk in U.S. Adults: 1999-2004 NHANES. Metab Syndr Relat Disord. 2007; 5 (4): 331-342.

8. Yasein $N$, Masa'd D. Metabolic syndrome in family practice in Jordan: a study of high-risk groups. East Mediterr Health J. 2011; 17 (12): 943-948.

9. Deen D. Metabolic syndrome: time for action. Am Fam Physician. 2004; 69 (12): 2875-2882.

10. Lewis SJ, Rodbard HW, Fox KM, Grandy S. Self-reported prevalence and awareness of metabolic syndrome: findings from SHIELD. Int J Clin Prac. 2008; 62 (8): 1168-1176.

11. Athyros VG, Ganotakis ES, Bathianaki M, Monedas I, Goudevenos IA, Papageorgiou AA, Papathanasiou A, Kakafika Al, Mikhailidis DP, Elisaf M. Awareness, treatment and control of the metabolic syndrome and its components: a multicentre Greek study. Hellenic $J$ Cardiol. 2005; 46 (6): 380-386.

12. Association WM. World Medical Association Declaration of Helsinki: ethical principles for medical research involving human subjects. JAMA. 2013; 310 (20): 21912194.

13. Alam MF, Nasreen S, Ullah E, Hussain A. The awareness and prevalence of metabolic syndrome in medical community of Bahawalpur. Oman Med J. 2011; 26 (1): 26.

14. Al-Aqeedi RF, Abdullatef WK, Dabdoob W, Bener A, Albinali $H A$, Gehani A. The prevalence of metabolic syndrome components, individually and in combination, in male patients admitted with acute coronary syndrome, without previous diagnosis of diabetes mellitus. Libyan $J$ Med. 2013; 8: 20185.

15. Sadrbafoghi SM, Salari M, Rafiee M, Namayandeh S.M, Abdoli A.M, Karimi M, Forouzannia S.KH. Prevalence and criteria of metabolic syndrome in an urban population: Yazd Healthy Heart Project. Tehran Univ Med J. 2006; 64 (10): 90-96.

16. Després J-P. Abdominal obesity: the most prevalent cause of the metabolic syndrome and related cardiometabolic risk. Eur Heart J Suppl 8. suppl B (2006): B4-B12.

17. Sobko T, Trindade D, Lao Q, Wong M, Io T, Wa C, GuK. Men in Macau SAR have higher prevalence in metabolic syndrome and among related metabolic components: a cross-sectional Macau Health Survey. BMC Public Health. 2014; 14 (1): 1065.

18. Ferguson TS, Younger N, Tulloch-Reid MK, Forrester TE, Cooper RS, Van den Broeck J, Wilks RJ. Prevalence of the metabolic syndrome in Jamaican adults and its relationship to income and education levels. West Indian Med J. 2010; 59 (3): 265-273.

19. Hunt KJ, Heiss G, Sholinsky PD, Province MA. Familial history of metabolic disorders and the multiple metabolic syndrome: the NHLBI family heart study. Genet Epidemiol. 2000; 19 (4): 395-409.

20. Shahbazian H, Latifi SM, Jalali MT, Shahbazian H, Amani $R$, Nikhoo A, Aleali AM. Metabolic syndrome and its correlated factors in an urban population in South West of Iran. J Diabetes Metab Disord. 2013; 12 (1): 11.

Trop J Pharm Res, September 2016; 15(9): 2006 
21. Villegas $R$, Perry IJ, Creagh D, Hinchion R, O'Halloran D. Prevalence of the Metabolic Syndrome in Middle-Aged Men and Women. Diabetes Care. 2003; 26 (11): 31983199.

22. Lee WY, Jung CH, Park JS, Rhee EJ, Kim SW. Effects of smoking, alcohol, exercise, education, and family history on the metabolic syndrome as defined by the ATP III. Diabetes Res Clin Pract. 2005; 67 (1): 70-77.

23. Rizzo NS, Sabaté J, Jaceldo-Siegl K, Fraser GE. Vegetarian Dietary Patterns Are Associated With a Lower Risk of Metabolic Syndrome: The Adventist
Health Study 2. Diabetes Care. 2011; 34 (5): 12251227.

24. Freiberg MS, Cabral HJ, Heeren TC, Vasan RS, Curtis Ellison R. Alcohol Consumption and the Prevalence of the Metabolic Syndrome in the U.S.: A cross-sectional analysis of data from the Third National Health and Nutrition Examination Survey. Diabetes Care. 2004; 27 (12): 2954-2959.

25. Kim BJ, Kim BS, Kang JH. Alcohol consumption and incidence of metabolic syndrome in korean men. A 3year follow-up study. Circ J. 2012; 76 (10): 2363-2371. 